Penelitian

\title{
Pengetahuan, Sikap, dan Praktik Peternak dalam Penggunaan Antibiotik pada Ayam Broiler di Kabupaten Subang
}

\section{Knowledge, Attitudes, and Practices of Broiler Commercial in The Use of Antibiotics in Subang District}

\author{
Trioso Purnawarman ${ }^{1^{*}}$, Rusman Efendi ${ }^{2}$ \\ ${ }^{1}$ Staf Pengajar Departemen Ilmu Penyakit Hewan dan Kesehatan Masyarakat Veteriner, \\ Fakultas Kedokteran Hewan, Institut Pertanian Bogor \\ ${ }^{2}$ Staf Pengajar Program Studi Kesehatan Masyarakat, Fakultas Kesehatan Masyarakat, \\ Universitas Muhammadiyah Jakarta \\ *Penulis untuk korespondensi: trioso18@yahoo.com \\ Diterima 15 Oktober 2020, Disetujui 17 November 2020
}

\begin{abstract}
ABSTRAK
Masalah global yang dihadapi saat ini adalah tingginya penggunaan antibiotik yang tidak tepat. Penggunaan antibiotik yang tidak rasional pada manusia dan hewan mendorong pada kejadian resistansi antibiotik. Penelitian ini bertujuan untuk menganalisis pengetahuan, sikap, serta hubungannya dengan praktik penggunaan antibiotik pada peternak broiler. Metode penelitian menggunakan desain cross sectional. Sampel dalam penelitian ini sebanyak 74 peternak dari 126 peternak di Kabupaten Subang. Kriteria sampel peternak yang diambil memiliki broiler 5000-10000 ekor. Teknik pengambilan sampel dilakukan dengan cara stratified random sampling berdasarkan pola manajemen peternakan, rincian besar sampel peternakan ayam broiler adalah 71 peternak dengan pola manajemen inti kemitraan dan pola menajemen mandiri sebanyak 3 peternak. Pengambilan dari dua kelompok tersebut dilakukan secara acak. Data diambil menggunakan kuesioner dengan cara wawancara, kemudian dianalisis dengan uji chi-square dengan tingkat kemaknaan $a \leq 0.05$. Hasil penelitian menemukan sebagian be sar peternak memiliki pengetahuan yang sedang tentang penggunaan antibiotik pada broiler. Peternak yang memiliki sikap baik dalam penggunaan antibiotik berjumlah berjumlah $7 \%$, paling sedikit bila dibandingkan dengan yang sikapnya sedang sebanyak $76 \%$ dan kurang sebanyak $17 \%$. Praktik peternak dalam menggunakan antibiotik pada broiler sebagian besar termasuk dalam kategorisedang. Terdapat hubungan yang bermakna antara pengetahuan dengan sikap peternak dalam penggunaan antibiotik pada broiler. Terdapat hubungan yang bermakna antara pengetahuan dengan praktik peternak dalam menggunakan antibiotik pada broiler dengan nilai $p=0.028 \leq 0.05$. Sikap tidak dengan praktik penggunaan antibiotik pada broiler. Kesimpulannya adalah pengetahuan berhubungan dengan praktik peternak dalam penggunaan antibiotik pada broiler
\end{abstract}

Kata kunci: pengetahuan, peternak, broiler, antibiotik, Subang

\begin{abstract}
The current global problem is the irrational high use of antibiotics. The irrational use of antibiotics in humans and animals leads to antibiotic resistance. This study aims to analyze knowledge, attitudes, and their relationship with the practice of using antibiotics in broiler breeders. The research method used a cross sectional design. The sample in this study were 74 farmers from 126 breeders in Subang Regency. Criteria for sample breeders taken have broilers 500010000 broilers. The sampling technique was stratified random sampling based on the farm management pattern, the details of the sample size of broiler chicken farms were 71 bree ders with a core management pattern of partnerships and 3 independent management patterns. The data were collected using a questionnaire with interviews, then analyzed using the chi-square test with a significance level of $\alpha \leq 0.05$. The results found that most breeders had moderate knowledge about the use of antibiotics in broilers. The number of breeders who had a good attitude in using antibiotics amounted to $7 \%$, the least when compared to $76 \%$ with moderate attitudes and $17 \%$ less. Farmer practices in using antibiotics in broilers are mostly included in the moderate cat egory. There is a significant relationship between knowledge and farmer attitudes in using antibiotics in broilers. There is a relationship between knowledge and farmer practices in using antibiotics in broilers. There is no relationship between attitude and practice of using antibiotics in broilers. The conclusion is that knowledge is related to farmer practices in using antibiotics in broil ers
\end{abstract}

Keywords: knowledge, farmers, broiler, antibiotic, Subang 


\section{PENDAHULUAN}

Penggunaan antibiotik merupakan salah satu cara untuk mengendalikan infeksi. Faktor penting dalam pengobatan penyakit infeksi adalah pemilihan antibiotik yang tepat. Masalah global yang dihadapi saat ini yaitu tingginya penggunaan antibiotik yang tidak tepat (Amin, 2014). Penggunaan antibiotik yang tidak rasional pada manusia dan hewan mendorong pada kejadian resistansi antibiotik. Hal tersebut merupakan ancaman serius bagi kesehatan dan kesejahteraan manusia serta merusak ekonomi nasional di seluruh dunia karena pengobatan akan menjadi lebih sulit dan membutuhkan biaya kesehatan yang lebih tinggi (Noor \& Poeloenga, 2014). Pada 2030, resistansi antimikroba bisa menyebabkan sebanyak 24 juta orang masuk ke dalam kemiskinan yang ekstrim. Saat ini, sedikitnya 700.000 orang meninggal setiap tahun karena penyakit yang resistansi obat (WHO, 2019).

Antibiotik selain digunakan sebagai pengobatan penyakit infeksi juga sebagai antibiotic growth promotor (AGP) yang meningkatkan kinerja pertumbuhan denganmeningkatkan kesehatan usus broiler, meningkatkan penyerapan dan pemanfaatan nutrisi. Penggunaan AGP adalah cara yang paling umum dan ekonomis untuk meningkatkan performa broiler (Debnath et al., 2014). Meskipun saat ini penggunaan antibiotik sebagai imbu han pakan telah dilarang dan penggunaan sebagai pengobatan harus dibawah pengawasan dokter hewan (Kementan, 2017), tetapi penggunaannya masih terindikasi kurang tepat. Penelitian Aniza et al. (2019) menemukan daging ayam broiler positif mengandung residu tetrasiklin yang melebihi batas maksimal residu kadar tetrasiklin.

Praktik penggunaan antibiotik oleh peternak yang tidak sesuai aturan merupakan faktor yang menyebabkan masih ditemukannya residu antibiotik pada daging broiler. Dari survei yang dilakukan oleh Huong-Anh et al. (2020) tentang pengetahuan, sikap, dan praktik pada 106 sampel daging ayam menunjukkan $27,4 \%$ sampel positif dengan 11 jenis antibiotik yaitu fluoroquinolones, sulfonamides, tetracycline, dan macrolides. Sebanyak 50,9\% peternak perlu meningkatkan pengetahuan mereka tentang penggunaan antibiotik yang tepat. Meskipun 54,7\% peternak bersikap positif, hanya $17 \%$ yang memiliki praktik yang baik. Penelitian Roth et al. (2019) dari hasil survei secara jelas menunjukkan tidak adanya pendekatan yang harmonis dalam pemantauan antibiotik per spesies hewan dan evaluasi resistensi.

Berdasarkan latar belakang diatas, penelitian pengetahuan sikap dan praktik penggunaan anti- biotik harus dilakukan untuk dapat melakukan intervensi yang tepat. Tujuan penelitian ini untuk menganalisis pengetahuan, sikap, serta hubungannya dengan praktik penggunaan antibiotik pada peternak ayam broiler.

\section{BAHAN DAN METODE}

Metode penelitian menggunakan desain cross sectional study yaitu variabel praktik penggunaan antibiotik, pengetahuan dan sikap diambil dalam satu periode waktu yang sama. Sampel dalam penelitian ini sebanyak 74 peternak dari 126 peternak di Kabupaten Subang. Kriteria sampel peternak yang diambil memiliki broiler 5000-10000 ekor. Teknik pengambilan sampel dilakukan dengan cara stratified random sampling berdasarkan pola manajemen peternakan, rincian besar sampel peternakan ayam broiler adalah 71 peternak dengan pola manajemen inti kemitraan dan pola menajemen mandiri sebanyak 3 peternak. Pengambilan dari dua kelompok tersebut dilakukan secara acak.

Data diambil menggunakan kuesioner dengan cara wawancara. Kuesioner dilakukan uji validitas dan reliabilitas untuk memastikan kelayakannya sebelum digunakan. Pengukuran pengetahuan tentang penggunaan antibiotik dilakukan dengan menggunakan 15 pertanyaan tertutup, sedangkan sikap terhadap penggunaan antibiotik diukur menggunakan 13 pernyataan sikap dengan tiga skala (setuju, ragu-ragu, dan tidak setuju). Pengukuran praktik penggunaan antibiotic menggunakan 6 kriteria pertanyaan. Peternak mendapatkan nilai baik jika mampu menjawab $75 \%-100 \%$ soal dengan benar, nilai sedang jika mampu menjawab 56\%-74\% soal dengan benar dan nilai kurang jika hanya mampu menjawab kurang dari $55 \%$ soal dengan benar.

Analisis data dilakukan secara univariat dan bivariat dengan uji chi-square untuk mengetahui hubungan antara pengetahuan dengan sikap, dan hubungan antara pengetahuan dan sikap dengan praktik penggunaan antibiotik. Kemaknaan Hubungan antar variabel ditentukan dengan $\alpha=0.05$. Bila nilai $p$ $\leq$ a maka terdapat hubungan yang bermakna.

\section{HASIL}

Berdasarkan hasil wawancara diperoleh data demografi peternak. Sebanyak 74 reponden sebagian besar adalah peternak berjenis kelamin laki-laki (91\%). Latar belakang Pendidikan peternak 
sebagian besar SMA (42\%). Umur responden sebagian besar berusia 30-50 tahun.

Jenis usaha kemitraan mendominasi sampel peternakan ayam broiler sebesar $96 \%$. Inti kemitraan memberikan bantuan serta menanggung biaya operasional yakni pakan dan obat-obatan, sedangkan peternakan mandiri ditanggung oleh masing-masing peternak. Peternak yang menjadi responden sebagian besar telah beternak selama lebih dari 5 tahun (66\%). Terdapat 18 (24\%) peternakan yang memiliki dukungan dokter hewan di lingkungan peternakannya.

Deskripsi Pengetahuan, Sikap, dan Praktik penggunaan antibiotik pada broiler

Berdasarkan hasil analisis kuesioner yang mengkategorikan Peternak mendapatkan nilai baik jika mampu menjawab 75\%-100\% soal dengan benar, nilai sedang jika mampu menjawab 56\%-74\% soal dengan benar dan nilai kurang jika hanya mampu menjawab kurang dari $55 \%$ soal dengan benar. Pengetahuan peternak tentang penggunaan antibiotik pada broiler di Kabupaten Subang sebagian besar termasuk kategori sedang. Jumlah peternak yang memiliki pengetahuan kurang lebih banyak bila dibandingkan dengan yang memiliki pengetahuan baik. Peternak yang memiliki sikap baik dalam penggunaan antibiotik berjumlah $7 \%$, paling sedikit bila dibandingkan dengan yang sikapnya sedang sebanyak $76 \%$ dan kurang sebanyak $17 \%$.

Praktik penggunaan antibiotik oleh petemak pada broiler sebagian besar termasuk dalam kategori sedang.
Peternak yang berpraktik baik dan kurang jumlahnya relatif sama yaitu 19\% dan 18\%. Secara lengkap hasil peneitian tentang pengetahuan, sikap, dan praktik penggunaan antibiotik pada broiler terlihat pada Tabel 1.

\section{Hubungan Pengetahuan dengan Sikap Penggunaan Antibiotic pada Broiler}

Peternak yang memiliki pengetahuan baik sebanyak 93,7\% memiliki sikap yang terkategori sedang dan tidak ada yang terkategori kurang dalam penggunaan antibiotik pada broiler. Peternak yang memiliki pengetahuan yang sedang menunjukan sikap yang terkategori sedang (82.5\%) dan kurang (15\%). Begitu juga peternak yang memiliki pengetahuan kurang memiliki sikap yang terkategori sedang (44.4\%) dan kurang (38.9\%) dalam penggunaan antibiotik. Pengujian dengan Uji chi square didapatkan nilai $p=0.005 \leq 0.05$, artinya ada hubungan yang bermakna antara pengetahuan dengan sikap peternak dalam penggunaan antibiotik pada broiler. Hasil penelitian secara lengkap disajikan pada Tabel 2.

\section{Hubungan Pengetahuan dengan Praktik Penggunaan Antibiotik pada Broiler}

Peternak yang memiliki pengetahuan baik lebih banyak yang berpraktik baik (44\%) dan sedang (44\%). Peternak yang memiliki pengetahuan kurang tidak ada yang berpraktik baik, tetapi berpraktik sedang (77.8\%) dan berpraktik kurang (22.2\%) dalam penggunaan antibiotik.

Tabel 1 Persentase pengetahuan, sikap, dan praktik dalam penggunaan antibiotik pada broiler

\begin{tabular}{lll}
\hline Peubah & Kategori & Frekuensi (\%) \\
\hline Pengetahuan & Baik & $16(22)$ \\
& Sedang & $40(54)$ \\
Sikap & Kurang & $18(24)$ \\
\cline { 2 - 3 } & Baik & $5(7)$ \\
& Sedang & $56(76)$ \\
Praktik & Kurang & $13(17)$ \\
\cline { 2 - 3 } & Baik & $14(19)$ \\
& Sedang & $47(63)$ \\
& Kurang & $13(18)$ \\
\hline
\end{tabular}


Pengetahuan, Sikap, dan Praktik Peternak | 51

Tabel 2 Hubungan tingkatpengetahuan dengan sikap peternak dalam penggunaan antibiotik pada broiler

\begin{tabular}{llllll}
\hline \multirow{2}{*}{ Pengetahuan } & \multicolumn{3}{c}{ Sikap } & Total & Nilai p \\
\cline { 2 - 4 } & Baik & Sedang & $0(0 \%)$ & 16 & $0.005^{*}$ \\
\hline Baik & $1(6.3 \%)$ & $15(93.7 \%)$ & $6(15 \%)$ & 40 & \\
Kurang & $1(2.5 \%)$ & $33(82.5 \%)$ & $7(38.9 \%)$ & 18 & \\
\hline
\end{tabular}

Keterangan: Nilai p yang diikuti tanda * menunjukan ada hubungan yang bermakna

Peternak yang memiliki pengetahuan sedang sebagian besar berpraktik sedang dalam penggunaan antibiotik pada broiler sebanyak 65\% seperti terlihat pada Tabel 3. Hasil uji chi square didapatkan nilai $\mathrm{p}$ sebesar $0,028 \leq 0.05$ yang berarti ada hubungan yang bermakna antara pengetahuan dengan praktik peternak dalam menggunakan antibiotik pada broiler.

\section{Hubungan Sikap dengan Praktik Penggunaan Antibiotik pada Broiler}

Sikap peternak yang baik sebagian besar berpraktik sedang sebesar $80 \%$, begitu juga yang bersikap sedang $63 \%$, dan kurang $61,6 \%$ berpraktik dalam kategori sedang dalam penggunaan antibiotik pada broiler seperti terlihat pada Tabel 3. Berdasarkan hasil uji chi square didapatkan nilai p sebesar $0.467 \geq$ 0.05 artinya tidak ada hubungan antara sikap dengan praktik penggunaan antibiotik pada broiler.

\section{PEMBAHASAN}

Deskripsi Pengetahuan, Sikap, dan Praktik penggunaan antibiotik pada broiler

Peternak yang memiliki pengetahuan dan sikap kurang jumlahnya lebih banyak bila dibandingkan dengan pengetahuan dan sikap baik, hal ini mungkin dikarenakan tingkat pendidikan dan pengalaman peternak. Menurut Walyani (2019) faktor yang mempengaruhi tingkat pengetahuan peternak antara lain pendidikan formal dan lama beternak. Semakin tinggi tingkat pendidikan formal semakin tinggi tingkat pengetahuan peternak. Semakin lama beternak semakin banyak informasi dan pengalamanan yang didapat oleh peternak.

Pengetahuan dan sikap yang kurang dapat menyebabkan praktikburukpenggunaan antibiotik sehingga menyebabkan residu antibiotik pada produk broiler yang membahayakan Kesehatan. Menurut Etikaningrum \& Iswantoro (2017) secara umum dampak negatif residu antibiotika pada produk hewan adalah dampak kesehatan (bahaya toksikologik, mikrobiologik dan imunopatologi) dan dampak ekonomi. Residu antibiotik juga dapat menyebabkan terjadinya resistansi antibiotik pada manusia (Ben et al., 2019).

Penelitian Wasnaeni et al. (2015) menemukan peternak broiler di Kecamatan Pengadegan, Kabupaten Purbalingga umumnya memiliki tingkat pengetahuan sedang. Peternak dengan sikap mendukung penggunaan antibiotik sebanyak $48,48 \%$, sedangkan yang kurang mendukung sebanyak $51,52 \%$. Penelitian Khan et al. (2018) menemukan 22,5\% peternak broiler memiliki pengetahuan tentang penggunaan antibiotik sebagai pemacu pertumbuhan. Hanya 7,5\% memahami istilah resistansi antibiotik dan $12 \%$ memiliki sedikit pengetahuan tentang bahaya kesehatan manusia setelah penggunaan antibiotik sembarangan. Hubungan antara penggunaan antibiotik pada ternak dan perkembangan resistensi antibiotik saat ini telah diakui secara luas (Landers et al., 2012).

Peternak dengan tingkat pendidikan formal yang lebih tinggi memiliki pengetahuan dan sikap yang jauh lebih baik daripada mereka yang berpendidikan lebih rendah (Pham-duc et al., 2019). Sebagian besar peternak unggas memiliki sikap positif terhadap penggunaan antibiotik yang baik dan sebagian besar peternak tidak 
Tabel 3 Hubungan tingkat pengetahuan, sikap dengan praktik peternak dalam men ggunakan antibiotik pada broiler

\begin{tabular}{|c|c|c|c|c|c|}
\hline \multirow[b]{2}{*}{ Pengetahuan } & \multicolumn{3}{|c|}{ Praktik } & \multirow{2}{*}{ Total } & \multirow{2}{*}{ Nilai $p$} \\
\hline & Baik & Sedang & Kurang & & \\
\hline Baik & $7(44.0 \%)$ & $7(44.0 \%)$ & $2(12.0 \%)$ & 16 & \multirow{3}{*}{$0.028 *$} \\
\hline Sedang & $7(17 \cdot 5 \%)$ & $26(65.0 \%)$ & $7(17.5 \%)$ & 40 & \\
\hline Kurang & $0(0.0 \%)$ & $14(77.8 \%)$ & $4(22.2 \%)$ & 18 & \\
\hline \multicolumn{5}{|l|}{ Sikap } & \multirow{4}{*}{0.467} \\
\hline Baik & $1(20.0 \%)$ & $4(80.0 \%)$ & $0(0.0 \%)$ & 5 & \\
\hline Sedang & $12(21 \%)$ & $35(63 \%)$ & $9(16 \%)$ & 56 & \\
\hline Kurang & $1(7.7 \%)$ & $8(61.6 \%)$ & $4(30.7 \%)$ & 13 & \\
\hline
\end{tabular}

Keterangan : Nilai p yang diikuti tanda * menunjukan ada hubungan yang bermakna

percaya adanya penggunaan antibiotik yang berlebihan pada unggas. Usia peternak merupakan faktor yang secara signifikan dikaitkan dengan sikap positif dalam penggunaan antibiotik yang baik. Petani yang lebih tua memiliki tingkat kesadaran, tingkat pengetahuan, dan sikap resistansi antibiotik yang jauh lebih tinggi daripada responden yang lebih muda (Al-Mustapha et al., 2020).

Peternak di Kabupaten Subang memiliki pengetahuan, sikap dan praktik penggunaan antibiotik yang terkategori sedang dan kurang. Hal tersebut kemungkinan karena faktor pendidikan yang masih rendah. Pendidikan merupakan landasan dasar bagi peternak untuk dapat mengembangkan pengetahuannya dalam beternak yang baik.

\section{Hubungan Pengetahuan dengan Sikap Penggunaan Antibiotic pada Broiler}

Hubungan yang bermakna antara pengetahuan dengan sikap peternak dalam penggunaan antibiotik dapat disebabkan berbagai faktor diantaranya oleh sikap masyarakat. Studi Lauwere \& Bokma (2019) menunjukkan bahwa sikap, persepsi dan preferensi peternak dapat membantu meningkatkan pengetahuan yang lebih baik untuk pengambilan keputusan oleh peternak. Secara umum masyarakat menyadari bahwa penggunaan antibiotik sebagai ancaman bagi kesehatan manusia, masyarakat merasakan risiko kesehatan manusia yang nyata dengan penggunaan antibiotik dalam peternakan (Busch et al., 2020).
Tingkat pengetahuan resistansi antibiotik secara signifikan berhubungan dengan persepsi peternak, tetapi pengetahuan tidak berhubungan dengan sikap penggunaan antibiotik dan resistansi antibiotik (Al-Mustapha et al., 2020). Pengetahuan, sikap, dan khususnya praktik sangat bervariasi di berbagai negara. Peternak unggas memiliki lebih banyak pengetahuan, sikap, dan praktik yang baik dibandingkan dengan peternak yang digembalakan (Caudell et al., 2020). Adanya hubungan pengetahuan tentang penggunaan antibiotik dengan sikap peternak di Kabupaten Subang dimungkinkan karena pengetahuan peternak akan membentuk keyakinan yang kemudian diekspresikan dalam bentuk sikap terhadap penggunaan antibiotik pada broiler.

Pengetahuan peternak menjadi penting untuk ditingkatkan karena akan mempengaruhi sikap peternak dalam menggunakan antibiotik yang masih kurang baik. Peternak beranggapan bahwa antibiotik dapat meningkatkan peroduktivitas, kondisi ayam yang tidak mau makan, mencegah ayam terjangkit penyakit, dan munculnya gejala penyakit pada ayam (Sumambang et al., 2019).

\section{Hubungan Pengetahuan dengan Praktik Penggunaan Antibiotik pada Broiler}

Adanya hubungan antara pengetahuan dengan praktik penggunaan antibiotik pada broiler karena pengetahuanyang baik tentang penggunaan antibiotik pada peternak akan mendorong peternak untuk 
berpraktik sesuai dengan apa yang diketahuinya. Intervensi praktik peternak seperti kampanye edukasi atau peningkatan dukungan oleh dokter hewan dapat memberdayakan peternak dengan praktik yang lebih bijaksana dan rasional, yang pada akhirnya mengurangi penggunaan antibiotik pada pakan ternak (Kramer et al., 2017).

Penelitian di berbagai negara menemukan bahwa tidak ada hubungan linier kausal antara pengetahuan, sikap dan praktik dalam berbagai survei (Kollef \& Fraser, 2001). Penelitian Nuangmek et al. (2018) menemukan sebagian besar peternak yang disurvei memiliki tingkat pengetahuan yang rendah, sikap netral, dan praktik menggunakan antimikroba yang buruk. Orang yang memiliki pengetahuan dan kesadaran yang kurang akan cenderung melakukan pengobatan sendiri yang kemudian dapat memicu terjadinya resistansi antbiotik (Wall, 2019).

Pengetahuan akan membentuk praktik penggunaan antibiotikyang baik pada peternak, sedangkan berkonsultasi dengan dokter hewan mungkin tidak meningkatkan praktik penggunaan antibiotik yang baik oleh peternak (Afakye et al., 2020). Hubungan bermakna antara pengetahuan dengan praktik penggunaan antibiotik pada broiler oleh peternak dapat disebabkan karena peternak akan melakukan apa yang diketahui tentang praktik penggunaan antibiotik. Pengetahuan tersebut dapat diperoleh dari berbagai informasi ataupun pengalaman yang didapatkan selama beternak. Informasi dari pemegang kebijakan penggunaan antibiotik merupakan salah satu yang dapat meningkatkan pengetahuan peternak.

\section{Hubungan Sikap dengan Praktik Penggunaan Antibiotik pada Broiler}

Menurut Ajzen (1991) bahwa praktik seseorang tidak hanya dipengaruhi oleh sikap dan pengetahuan, tetapi ada faktor niat, norma subjektif dan persepsi kontrol perilaku. Sehingga tidak adanya hubungan antara sikap peternak dengan kemungkinan disebabkan oleh faktor lain. Pada penelitian Thongpalad et al. (2019) diketahui ada perbedaan sikap yang signifikan antara peternak yang menerapkan cara beternak yang baik dengan peternak yang tidak menerapkan cara beternak yang baik.

Menurut Irawati et al. (2020) praktik peternak inti plasma sangat dipengaruhi oleh perusahaan induk, meskipun secara sikap dapat saja berbeda dengan perusahaan induk. Hal ini disebabkan karena peternakan pola inti plasma kemitraan ayam broiler yang berjalan selama ini disediakan sarana produksi peternakan termasuk obat-obatan oleh perusahaan induk, sedangkan peternak plasma cukup menyediakan kandang dan tenaga kerja. Penelitian Afakye et al. (2020) menemukan hubungan pengetahuan, sikap, dengan praktik pengobatan menggunakan antibiotik, tetapi dalam praktik pengobatan para peternak lebih sering berkonsultasi dengan dokter hewan komunitas. Selain sikap, ketidakpastian diagnostik juga sering menjadi pendorong terhadap penggunaan obatobatan yang tidak benar (Hulscher et al., 2010).

Praktik peternak dalam menggunakan antibiotik juga dapat dipengaruhi oleh dorongan produsen antibiotik. 1,5 juta kg bahan antimikroba aktif didistribusikan untuk digunakan pada hewan di Kanada. Antimikroba yang didistribusikan, 99\% untuk hewan ternak dan kurang dari $1 \%$ untuk hewan peliharaan (Mehdi et al., 2018). Banyaknya ketersedian antibiotik, dan pengalaman peternak dalam menggu-nakan antibiotik yang menguntungkan tentunya akan mendorong peternak untuk menggunakan antibiotik.

Menurut Coyne et al. (2020) banyaknya peternak yang menggunakan antibiotik pada broiler dikarenakan antibiotik sangat mudah untuk didapatkan, sedangkan untuk mendapatkan saran dari dokter hewan sulit untuk diakses. Dalam survei pengetahuan, sikap dan resep antibiotik di antara para dokter Jamaika $82 \%$ menganggap resistansi antibiotik penting secara global, $73 \%$ penting secara nasional dan $53 \%$ penting dalam praktik pribadi mereka (Nicholson et al., 2018).

Faktor sikap tidak menunjukan adanya hubungan dengan praktik peternak dalam menggunakan antibiotik. Hal ini mungkin dikarenakan sebagian besar dari peternak merupakan peternak plasma kemitraan, sehingga kemungkinan faktor manajemen yang terpusatlah yang akan menentukan praktik peternak dalam menggunakan antibiotik pada broiler.

Dari hasil penelitian ini dapat disimpulkan bahwa sebagian besar peternak memiliki pengetahuan, sikap dan praktik penggunaan antibiotik yang terkategori sedang. Terdapat hubungan yang bermakna antara pengetahuan dengan sikap peternak dalam penggunaan antibiotik pada broiler, dan juga terdapat hubungan yang bermakna antara pengetahuan dengan praktik peternak dalam penggunaan antibiotik pada broiler. Sikap tidak menunjukan adanya hubungan dengan praktik peternak dalam menggunakan antibiotik pada broiler. 
"Penulis menyatakan tidak ada konflik kepentingan dengan pihak-pihak yang terkait dalam penelitian ini".

\section{DAFTAR PUSTAKA}

Afakye K, KiambiS, Koka E, Kabali E, Dorado-Garcia A, Amoah A, Kimani T, Adjei B, Caudell MA. 2020. The impacts of animal health service providers on antimicrobial use attitudes and practices: An examination of poultry layer farmers in Ghana and Kenya. Antibiotics 9(9): 554.

Ajzen I. 1991. The theory of planned behavior. Organ Behav Hum Decis Process 50(11): 179-211.

Al-Mustapha Al, Adetunji VO, Heikinheimo A. 2020. Risk perceptions of antibiotic usage and resistance: a cross-sectional survey of poultry farmers in Kwara State, Nigeria. Antibiotics 9(7): 1-10.

Amin L. 2014. Pemilihan antibiotik yang rasional. Medicinus 27(3): 40-45.

Aniza SN, Andini A, Lestari I. 2019. Analisis residu antibiotik tetrasiklin pada daging ayam broiler dan daging sapi. J Sain Health 3(2): 22-32.

Ben $\mathrm{Y}$, Fu C, Hu M, Liu L, Wong MH, Zheng C. 2019. Human health risk assessment of antibiotic resistance associated with antibiotic residues in the environment: A review. Environ Res 169: 483-493.

Busch G, Kassas B, Palma MA, Risius A. 2020. Perceptions of antibiotic use in livestock farming in Germany, Italy and the United States. Livest Sci 241(September): 104251.

Caudell MA, Dorado-Garcia A, Eckford S, Creese C, Byarugaba DK, Afakye K, Chansa-Kabali T, Fasina FO, Kabali E, KiambiS, et al.2020. Towards a bottom-up understanding of antimicrobial use and re sistance on the farm: A knowledge, attitudes, and practices survey across livestock systems in five African countries. PLoS One 15(1): 1-26.

Coyne L, Patrick I, Arief R, Benigno C, Kalpravidh W, McGrane J, Schoonman L, Sukarno AH, Rushton J. 2020. The costs, benefits and human behaviours for antimicrobial use in small commercial broiler chicken systems in Indonesia. Antibiotics 9(4): 1-17.

Debnath B, Choudhary KB, Ravikanth K, Thakur A, Maini S. 2014. Comparative efficacy of natural growth promoter $(\mathrm{Av} / \mathrm{Agp} / 10)$ with antibiotic growth promoter on overall growth performance and intestinal morphometry in broiler birds. Int J Pharm Sci Heal Care 2(4): 155-168.

Etikaningrum, Iswantoro S. 2017. Kajian residu antibiotika pada produk ternak unggas di Indonesia.
Jurnal Ilmu Produksi dan Teknologi Hasil Peternakan 5(1): 29-33.

Hulscher ME, Grol RP, van der Meer JW. 2010. Antibiotic prescribing in hospitals: A social and behavioural scientific approach. Lancet Infect Dis

Huong-Anh NT, Chinh D Van, Tuyet-Hanh TT. 2020. Antibiotic residues in chickens and farmers' knowledge of their use in Tay Ninh Province, $\mathrm{Vi}$ etnam, in 2017. Asia-Pacific J Public Heal 32(2-3): 126-132.

Irawati E, Fitra D, Kantra I. 2020. Analisis kepuasan peternak plasma terhadap kinerja kemitraan ayam pedaging di Kabupaten Kampar Provinsi Riau. Jurnal Peternakan 17(2): 64-71.

Kementan. 2017. Peraturan Menteri Pertanian Republik Indonesia Nomor 14/PERMENTAN/PK. 350/5/2017 Tentang Klasifikasi Obat Hewan.

Khan M, Ferdous J, Ferdous M, Islam M, Rafiq K, Rima U. 2018. Study on indiscriminate use of antibiotics in poultry feed and residues in broilers of Mymensingh city in Bangladesh. Progress Agric 29(4): 345-352.

Kollef MH, Fraser VJ. 2001. Antibiotic resistance in the intensive care unit. Ann Intern Med 134(4): 298-314.

Kramer T, Jansen LE, Lipman LJA, Smit LAM, Heederik DJJ, Dorado-García A. 2017. Farmers' knowledge and expectations of antimicrobial use and resistance are strongly related to usage in Dutch livestock sectors. Prev Vet Med 147(August): 142-148.

Landers TF, Cohen B, Wittum TE, Larson EL. 2012. A review of antibiotic use in food animals: Perspective, policy, and potential. Public Health Rep 127(1): 4-22.

Lauwere C de, Bokma M. 2019. Behavioural Factors Affecting Broiler Farmers' Decision Making with Regard to Reduction of Antibiotics Use in the Netherlands. Seminar. Swedish University of Agricultural Sciences, Swedish University of Agricultural Sciences.

Mehdi Y, Létourneau-Montminy MP, Gaucher M Lou, Chorfi Y, Suresh G, Rouissi T, Brar SK, Côté C, Ramirez AA, Godbout S. 2018. Use of antibiotics in broiler production: Global impacts and alternatives. Anim Nutr 4(2): 170-178.

Nicholson A, Tennant I, White L, Thoms-Rodriguez CA, Cook L, Johnson S, Thompson T, Barnett J, Richards L. 2018. The knowledge, attitudes and practices of doctors regarding antibiotic resistance at a tertiary care institution in the Caribbean. Antimicrob Resist Infect Control 7(1): 1-9. 
Noor SM, Poeloenga M. 2014. Pemakaian Antibiotika Pada Ternak. Lokakarya Nas Keamanan Pangan Prod Peternak 56-64.

Nuangmek A, Rojanasthien S, Chotinun S, Yamsakul P, Tadee P, Thamlikitkul V, Tansakul N, Patchanee P. 2018. Antimicrobial resistance in ESBLproducing Escherichia coli Isolated from layer and pig farms in Thailand. Acta Sci Vet 46(1): 1-8.

Pham-duc P, Id MAC, Cong-hong H, Nguyen-thuy H. 2019. Knowledge, attitudes and practices of livestock and aquaculture producers regarding antimicrobial use and resistance in Vietnam. PLoS One 14(9): 1-21.

Roth N, K"asbohrer A, Mayrhofer S, Zitz U, Hofacre C, Domig KJ. 2019 The application of antibiotics in broiler production and the resulting antibiotic resistance in Escherichia coli: A global overview. Poultry Science 98: 1791-1804.

Sumambang A, Ariyanto A, Kompudu A, Pangaribuan D, Nugroho E, Puspita R, Ulfa D. 2019. Persepsi Peternak Terhadap Penggunaan Antibiotik Pada Peternakan Ayam Pedaging Komersial Di Provinsi Kalimantan Barat. Prosiding Penyidikan Penyakit Hewan Rapat Teknis dan Pertemuan
Ilmiah (RATEKPIL) dan Surveilans Kesehatan Hewan Tahun 2019: 482-488.

Thongpalad K, Kuwornu JKM, Datta A, Chulakasian S, Anal AK. 2019. On-farm food safety knowledge, attitudes and self-reported practices of layer hen farmers. Br Food J 121(8): 1912-1925.

Wall S. 2019. Prevention of antibiotic resistance - an epidemiological scoping review to identify research categories and knowledge gaps. Glob Health Action 12(1): 1756191.

Walyani S. 2019. Faktor yang Berpengaruh Terhadap Resistensi Antibiotik pada Salmonella spp. di Peternakan Broiler di Kabupaten Subang. Prosiding Ratekpil dan Surveilans Kesehatan Kesehatan Hewan tahun 2019: 474-481.

Wasnaeni Y, Iqbal A, Ismoyowati I. 2015. Broiler farmers' behavior in administering antibiotic and types of antibiotic content in commercial feed (A case study). Anim Prod 17(1): 62.

WHO. 2019. New Report Calls for Urgent Action to Avert Antimicrobial Resistance Crisis.https://www.who.int/news-room/detail/2904-2019-new-report-calls-for-urgent-action-toavert-antimicrobial-resistance-crisis.Download: October 5, 2020. 